\title{
TRANÇADO: RECURSOS COMPUTACIONAIS APLICADOS NO PROCESSO DE PROJETO DE UM MOBILIÁRIO URBANO
}

\section{TRANÇADO: COMPUTATIONAL DESIGN THINKING APPLIED TO} A URBAN FURNITURE PROJECT

\section{Dyego Digiandomenico', Gabriele Landim', Henrique Fischer²}

RESUMO: Este trabalho apresenta a pesquisa, projeto e construção do mobiliário urbano Trançado, localizado no Largo da Batata, um espaço público na cidade de São Paulo. O artigo discute o desenvolvimento do algoritmo, os parâmetros, a performance do projeto e o uso das tecnologias de prototipagem rápida e da fabricação digital para a análise do modelo e das técnicas construtivas, assim como descreve detalhes da execução e instalação final. Oferece também dados da pesquisa de pós-ocupação, assim como discute a relação entre o projeto do mobiliário e seu uso real, visto que participaram do processo agentes de diferentes áreas, como profissionais, organizações e sociedade civil. A pesquisa contribui ao relatar e discutir a qualidade do processo aplicado, não se concentrando apenas em analisar o resultado do objeto arquitetônico, mas produzir insumos para a reflexão e avanço da aplicação dos recursos computacionais no processo de projeto em arquitetura e design.

PALAVRAS-CHAVE: Mobiliário Urbano; Design Computacional; Modelagem Paramétrica; Arquitetura Algorítmica; Processos Colaborativos.

ABSTRACT: This study presents the research, project and construction of the urban furniture project of Trançado, located in the Largo da Batata, a public space of the city of São Paulo. The article discusses the development of the algorithm, parameters and performance of the project and the use of rapid prototyping and digital fabrication technologies for model analysis and construction techniques, as well as details of the final assembling. It also provides post-occupation data and discusses the relationship between design process and actual use of the furniture. Stakeholders from different areas were involved: professionals, organizations and citizens. The research contributes reporting and discussing the quality of the applied process, not only focusing on analyzing the results of the final object, but producing inputs for reflection and progress of the application of computational design thinking in the architectural design process.

KEYWORDS: Urban Furniture; Computational Design; Parametric Modelling; Algorithmic Architecture; Collaborative Processes. 


\section{INTRODUÇÃO}

Durante mais de dez anos, a região do Largo da Batata passou por intensas intervenções urbanísticas decorrentes da Operação Urbana Consorciada Faria Lima, que, segundo descrição oficial, tinha por objetivo principal reorganizar os fluxos de tráfego particular e coletivo ao implantar o prolongamento da avenida Faria Lima, na cidade de São Paulo. No entanto, após a finalização das obras públicas, em 2013, o Largo da Batata, que antes era um lugar ativo e rico em atividades comerciais formais e informais, passou a ser um grande vazio pavimentado e espaço de passagem. Sem mobiliário, vegetação e instalações que possibilitassem a convivência e permanência dos visitantes e transeuntes, os moradores do entorno e frequentadores da região passaram a questionar o projeto final e o real caráter de praça pública do largo.

Durante os últimos anos, iniciativas civis de discussão sobre o uso da praça reuniram pessoas interessadas na ativação do espaço, que se organizaram e iniciaram intervenções de apropriação. Uma destas iniciativas resultou no concurso Batatalab. Segundo o instituto organizador, A Cidade Precisa de Você (2015), o tema do concurso, "Sombra", foi definido a partir de uma pesquisa de dois meses com os frequentadores do largo sobre o que mais desejavam no local, tendo como solicitações principais a necessidade de lugares para sentar e encostar, áreas arborizadas e sombreadas e equipamentos infantis.

Assim, o projeto Trançado foi inserido como parte de uma iniciativa sem fins lucrativos de ocupação e apropriação do espaço público do Largo da Batata, promovida pelo concurso Batatalab, realizado pelo coletivo A Cidade Precisa de Você e o Instituto de Pesquisa e Inovação em Urbanismo (Ipiu).

É relevante apresentar ao leitor os dois pontos de observação que conduziram o projeto Trançado, pois, tratando-se de uma intervenção no espaço público, é necessária uma visão sistêmica que observe o trabalho contínuo, iniciado antes da instalação dos mobiliários.

O primeiro ponto importante é compreender o processo de transformação do local e as emergências surgidas a partir desse processo. Nesta escala estão envolvidos agentes que dão caráter complexo às transformações urbanas, nas esferas sociais, econômicas e políticas, em um processo já iniciado e que ainda se desenvolve. O segundo ponto é compreender todo o nível anterior, somado a uma série de necessidades funcionais, como aspectos técnicos de aprovação do projeto na subprefeitura do bairro, orçamento disponível, prazos de entrega e instalação, técnicas construtivas e solicitações funcionais do edital do concurso.

Faz parte da discussão deste artigo compreender e explicitar que o mobiliário não atende somente a aspectos técnicos e funcionais, tendo como objetivo final não só a instalação-objeto, mas um projeto que, em conjunto com os outros mobiliários instalados, contribui como uma interface na configuração geral do espaço, estimulando o convívio, as trocas e os debates.

$\mathrm{O}$ estado atual da arquitetura é certamente resultado de um processo bastante longo e complexo. As transformações de paradigma no processo de projeto de arquitetura é fruto de pesquisas desenvolvidas nas últimas décadas e de intrincadas relações entre tecnologias da informação, comunicação, computação, manufaturas, interfaces, conectividade e outros processos.

A fim de integrar o processo de projeto e os recursos computacionais que atualmente fazem parte das investigações das práticas de design contemporâneas, o presente artigo descreve o sistema de modelagem paramétrica, a prototipagem rápida de modelo em escala como processo auxiliar de projeto e os problemas reais encontrados durante o processo de concepção, fabricação e instalação do mobiliário urbano Trançado, no Largo da Batata, na cidade de São Paulo (Figura 1). 


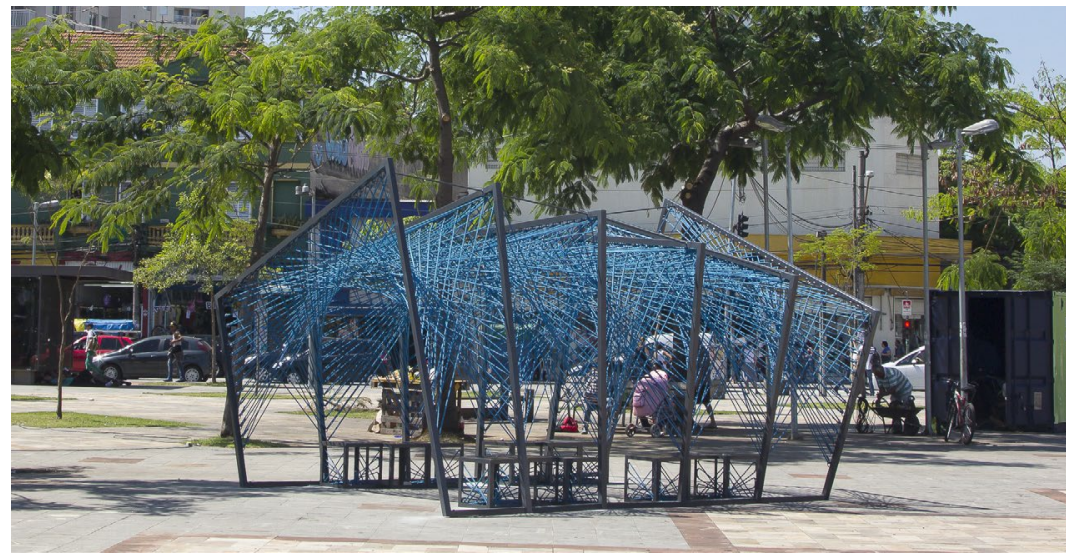

O concurso teve o objetivo de testar três aspectos: "a promoção do convívio entre as pessoas, o efeito do design na perspectiva da população e a replicabilidade para outros espaços públicos de São Paulo" (ANTUNES; SOBRAL; KARPISCHEK, 2016, p. 6).

O projeto do mobiliário foi proposto ao concurso por três arquitetos pesquisadores que formam o Quasares, um coletivo de pesquisa autônomo, formado a partir da reunião de pessoas interessadas no uso de tecnologia computacional nos processos de projeto.

O método utilizado na concepção do projeto pode ser chamado de design computacional ou computational design thinking (CASTELLANO, 2011; OXMAN, 2006; OXMAN; GU, 2015), e seu potencial está direcionado em prover soluções mais completas e otimizar variáveis de maneira holística.

Embora muito utilizada nos últimos anos, principalmente em pesquisas acadêmicas em todo o mundo, a modelagem paramétrica ainda não faz parte da prática de projeto da grande maioria dos arquitetos brasileiros, apresentando ainda grande campo de discussão não explorado na aplicação de recursos computacionais.

A contribuição desta pesquisa é a de relatar e discutir a qualidade do processo em vez de apenas analisar seu resultado final, produzindo insumos para a reflexão e o avanço da aplicação dos recursos computacionais no processo de projeto de mobiliários urbanos.

\section{METODOLOGIA}

Esta pesquisa foi realizada através de abordagem exploratória com foco em identificar a eficiência dos métodos e técnicas computacionais empregadas na concepção e produção do objeto arquitetônico estudado.

Os objetivos do projeto embasam a compreensão da leitura do mobiliário enquanto experimento de métodos e técnicas do design computacional. São eles: (1) fortalecer e dar suporte a um laboratório de inovação em mobiliário urbano, no Largo da Batata, que sirva como território de testes para inspirar a melhoria de outros espaços públicos; (2) promover a pesquisa de novas tecnologias e aplicações na construção, tal como em estruturas, revestimentos, sistema de implantação e o seu desenvolvimento em uma concepção arquitetônica e estrutural apropriada; (3) promover a pesquisa de materiais e componentes construtivos e seu potencial de replicabilidade em mobiliários urbanos de praças, parques e calçadas (INSTITUTO A CIDADE PRECISA DE VOCÊ; INSTITUTO DE PESQUISA E INOVAÇÃO EM URBANISMO, 2015).

A partir dos objetivos elencados, a equipe de arquitetos realizou um planejamento para identificar, delimitar e incorporar os critérios que atuavam em cada uma das etapas do processo de projeto, que considerou
Figura 1: Foto do mobiliário Trançado

Fonte: Rogério Canella 
Figura 2: Fluxograma de etapas do processo de projeto

Fonte: Elaborada pelos autores também a expertise de membros dos institutos e do poder público. Nesse processo, foram utilizados recursos computacionais que viabilizaram a utilização do pensamento algorítmico na construção das etapas e suas relações com todo o processo, além da parametrização na manipulação das variáveis, formalizadas através da programação visual no editor gráfico de algoritmos Grasshopper e no programa de modelagem em CAD Rhinoceros.

Os métodos e técnicas apresentados a seguir abordam desde o processo de concepção até a materialização e instalação do mobiliário em escala real, entregue como um mobiliário ao espaço público da cidade. É possível delimitar as seguintes etapas de descrição do processo de projeto: concepção, desenvolvimento, revisão (feedback), prototipagem e execução/ instalação (Figura 2).

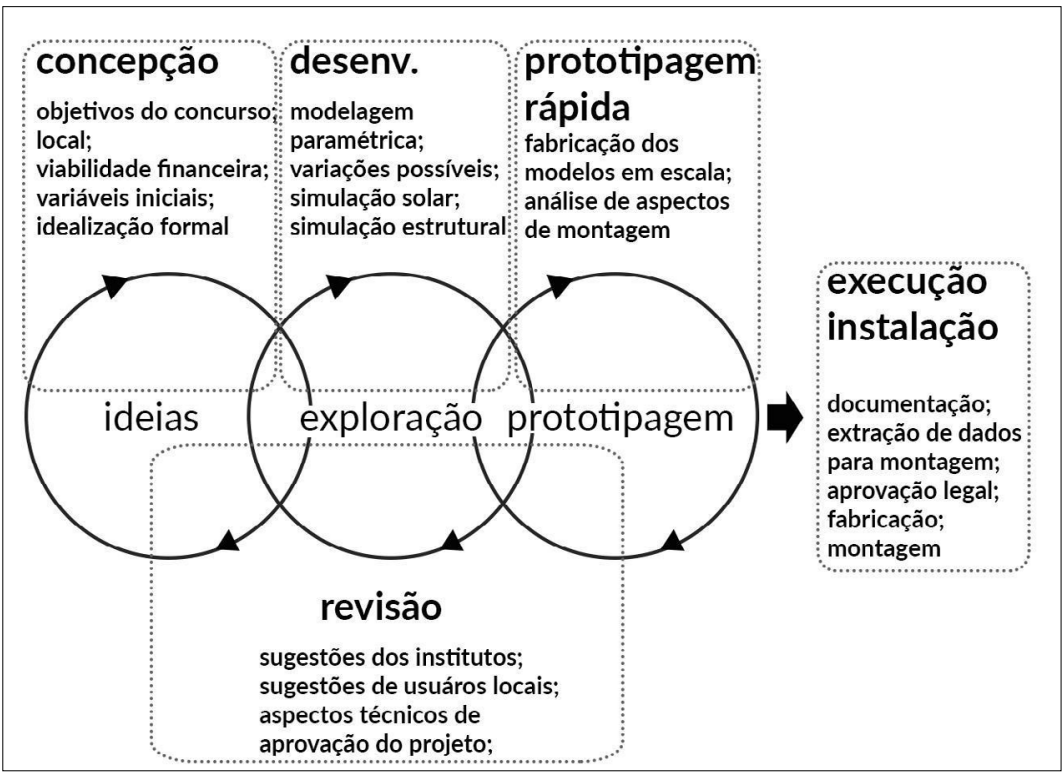

A concepção do projeto se embasou não só nos objetivos do concurso, mas também em questões funcionais de uso e instalação e nas características do próprio local de implantação, sem deixar de equalizar a viabilidade financeira da proposta. No desenvolvimento, foram consideradas desde a modelagem paramétrica do objeto até as simulações de insolação. Estas duas etapas foram anteriores à submissão do projeto no concurso, durando aproximadamente um mês.

Após a seleção da proposta pelo júri, houve uma revisão de acordo com novas informações que surgiram a partir de um maior contato com os usuários da praça e do retorno do próprio instituto. A partir desse ponto, o projeto evoluiu para a etapa de execução, gerando a documentação necessária para a aprovação dos órgãos competentes, orçamentos detalhados, fabricação e montagem. Do resultado do concurso até a instalação do mobiliário, as fases descritas foram executadas em aproximadamente quarenta e cinco dias.

\section{RESULTADOS}

\section{Concepção}

Entre os principais critérios que o processo de projeto levou em conta na sua concepção, com o amparo dos recursos computacionais, estão: 
1) as condições climáticas e a relação com o entorno: privilegiar a permeabilidade com aberturas e eixos visuais na mesma medida em que sombra e conforto ambiental são proporcionados ao usuário;

2) a função do mobiliário e sua apropriação pelos usuários: reforçar a intenção do mobiliário de ser confortável para o encontro e a permanência, ao mesmo tempo que possui elementos que despertam a curiosidade e o caráter lúdico da instalação, explorando a complexidade formal do trançado que o recobre;

3) soluções estruturais: compor através de encaixes simples e componentes leves um sistema estrutural harmônico com o design do projeto e que seja capaz de resistir às cargas, esforços e intempéries no espaço público;

4) material e acabamento: garantir a durabilidade do mobiliário e propor o uso de materiais mais leves, que não são comumente utilizados em mobiliários públicos;

5) viabilidade econômica e de fabricação: todas as questões conceituais, funcionais e técnicas devem ser contempladas dentro de um orçamento limitado, definido pelo edital do concurso.

A partir do atrelamento dos parâmetros levantados pela equipe com a capacidade dos recursos computacionais, foi possível explorar a complexidade formal do mobiliário, incorporando aspectos que pudessem transcender o caráter funcional e conferissem o aspecto de experiência aos usuários do local. É nesse sentido de interface que o ciberneticista Klaus Krippendorff (2004) sugere a importância das motivações "intrínsecas” no design, que vão além das motivações “extrínsecas”, citadas pelo autor como os aspectos funcionalistas de um projeto, inseridos para justificar diretamente os resultados finais do objeto. Segundo o autor, "as experiências ótimas, o prazer de estar, a satisfação no trabalho, o desfrutar, a emoção e diversão, são intrinsecamente motivadores e são importantes forças motrizes da tecnologia, embora não reconhecíveis por métodos empíricos que celebram o extrínseco e destituem a motivação intrínseca” (KRIPPENDORFF, 2004, p. 54).

\section{Desenvolvimento}

O projeto foi desenvolvido remotamente entre a equipe, separada entre as cidades de São Paulo e Buenos Aires. Para isso, foi necessário estabelecer o método de compartilhamento e colaboração do modelo paramétrico. Foram utilizados os conceitos de organização em programação modular definidos por Daniel Davis, Jane Burry e Mark Burry (2011), e todas as ações do algoritmo foram organizadas contendo: títulos, entradas, saídas, grupo e descrição. Embora trabalhar com o agrupamento dos nós seja uma tarefa simples, os autores afirmam que esse esquema "pode aumentar significativamente a legibilidade de um modelo, o que torna mais fácil seu compartilhamento de forma colaborativa” (DAVIS; BURRY; BURRY, 2011, p. 66).

As principais características técnico-construtivas e as relações subjetivas citadas foram interpretadas pelos arquitetos e declaradas em um encadeamento de parâmetros através da programação visual. Os cruzamentos desses parâmetros deram luz às primeiras investigações e testes de desempenho da forma inicial.

As variáveis, conforme eram inseridas e consideradas no projeto, interferiam diretamente na forma, porém mantinham relações de negociação e balanceamento estipuladas pelos arquitetos, para que todo o resultado fosse reflexo das necessidades informadas. Este é um conceito básico da parametrização, onde se estabelece as relações pelas quais as partes se conectam, permitindo que o sistema projetado se encarregue de manter as concepções consistentes com as relações (WOODBURY, 2010, p. 24). 
Um exemplo claro dessa relação entre os elementoslistados anteriormente foi a inserção dos parâmetros que configuraram o posicionamento e complexidade do trançado das cordas na cobertura e a relação de rotação entre os pórticos estruturais, um cruzamento de três variáveis: a posição e distribuição do encordoamento em relação aos índices de incidência solar simulados computacionalmente; a quantidade e diâmetro do material de encordoamento; o desempenho estrutural simulado do posicionamento dos pórticos verticais em relação às dimensões gerais do mobiliário; e as cargas decorrentes da própria estrutura e da quantidade de cordas.

\section{Revisão}

Após o anúncio do projeto selecionado pelo júri do concurso, ao longo do desenvolvimento do projeto executivo, a equipe passou a estabelecer contato com os membros dos institutos e do movimento civil que atua na região.

O design computacional possibilitou, nesta fase, um retorno de informações obtidas ao longo das conversas e feedbacks entre os envolvidos. As mudanças e aprimoramentos do projeto puderam ser inseridos como variáveis modificadas, assim, as simulações eram facilmente recalculadas e as novas relações que ainda não estavam declaradas poderiam ser inseridas no algoritmo, aproveitando os dados e relações existentes.

Este processo de revisão é natural no processo de projeto, pois, nas etapas iniciais das propostas, é comum que os problemas de concepção não possam ser formulados de forma abrangente (LAWSON, 2005). Porém, no método tradicional de projeto, a viabilidade dessas transformações seria muito trabalhosa e praticamente impossível, devido à complexidade formal do mobiliário, o encadeamento de parâmetros e os prazos do concurso.

Como exemplos de dados que passaram a informar o projeto após o contato das equipes, podemos citar: posicionamento e implantação, que resultaram em ajustes no posicionamento e quantidade de pórticos verticais; cores e acabamentos dos materiais; fixação e montagem.

\section{Uso das tecnologias de prototipagem rápida e fabricação digital}

O uso da modelagem paramétrica na concepção de projeto fornece dados e geometrias que podem ser materializadas de maneira direta, rápida e automatizada com a fabricação digital dos modelos em escala.

Essa fase se torna fundamental durante o processo de projeto, pois permite ao projetista observar o modelo em escala e elucidar uma série de problemáticas das fases de concepção e desenvolvimento que não eram possíveis de serem identificadas com facilidade no modelo digital.

No desenvolvimento do projeto, os usos da prototipagem rápida com fabricação digital aconteceram em dois momentos. O primeiro foi a produção do modelo em escala 1:9, utilizando a máquina de corte a laser em madeira MDF 3 milímetros (Figura 3). Por se tratar de uma tecnologia de corte 2D, foi adicionada ao algoritmo a planificação das peças estruturais e a disposição na placa para o corte. Foram produzidos simultaneamente dois modelos em escala, um em cada cidade, para que a equipe pudesse continuar o desenvolvimento em consonância. Esta fase foi fundamental à viabilidade da construção real, pois foi possível prever aspectos da fixação e ordem de montagem do projeto final.

Foi identificada a necessidade de inversão da ordem das camadas do trançado. No modelo em escala, a ordem de trançado prevista inicialmente parecia adequada, pois era trançada por quem via o modelo de cima, porém, para a montagem in loco, seria necessário começar da camada de cordas que alcançariam o ponto mais alto da estrutura. Foram realizados ajustes na ordem das listas de dados, a fim de viabilizar a construção real. 


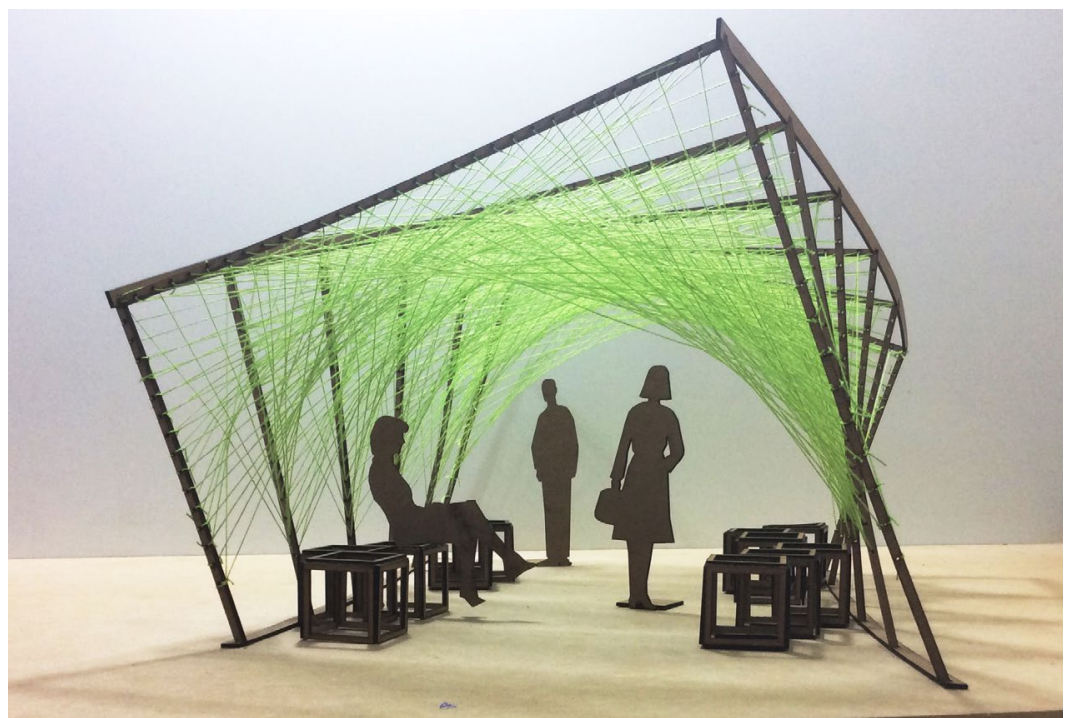

O segundo momento de aplicação da fabricação digital foi na prototipagem de trechos da estrutura em escala real, utilizando impressão 3D para o estudo de viabilidade da fixação do encordoamento e montagem dos pórticos estruturais (Figura 4). A prototipagem deu subsídios para a tentativa de viabilizar a produção final da estrutura do mobiliário com fabricação digital, com corte a plasma das chapas e de seus respectivos furos de fixação do encordoamento e formação das partes da estrutura com as chapas dobradas em dobradeiras CNC. No entanto, com a análise de todos os parâmetros obtidos até esta fase, foi identificado que a fabricação digital do mobiliário não seria viável financeiramente, e os prazos seriam incompatíveis com os adotados pelas indústrias que poderiam prestar esse serviço.

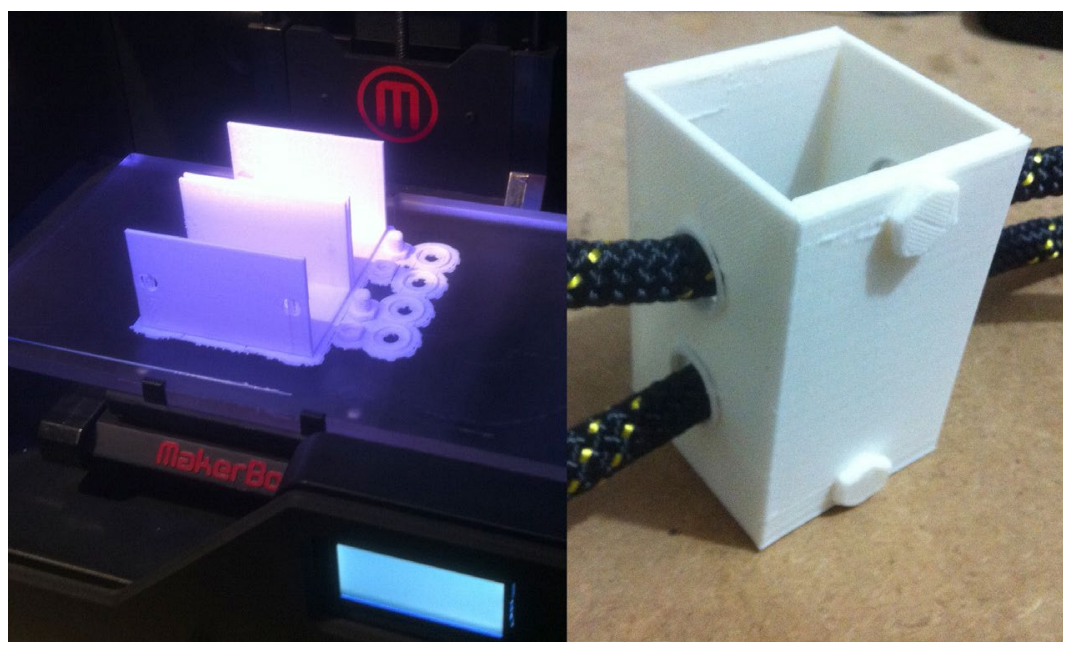

Sendo assim, foram reinseridos parâmetros no modelo a fim de readequá-lo à fabricação com perfis comerciais pré-fabricados, além da mudança da fixação do encordoamento através de argolas metálicas fabricadas pela serralheria. Os cálculos estruturais de desempenho dos novos perfis foram refeitos e o projeto passou da fase de finalização para o início da fabricação e montagem.

\section{Execução e instalação}

A estrutura do projeto é composta por seis pórticos metálicos verticais, posicionados paralelamente uns aos outros, fixados com travamentos
Figura 3: Modelo em escala 1:9 produzido com máquina de corte a laser

Fonte: Elaborada pelos autores do projeto

Figura 4: Protótipo em escala 1:1 produzido por impressão 3D Fonte: Elaborada pelos autores do projeto 
superiores em barra de ferro redondo e travamentos inferiores em barras metálicas de seção quadrada. Ao longo de cada pórtico, estão posicionadas argolas metálicas, que orientam o trançado das cordas de polietileno.

Para dar início à fabricação e montagem do projeto pelo serralheiro, foi necessário gerar a documentação tradicional de arquitetura, indicando os ângulos e cortes necessários para a fabricação, assim como o passo a passo da montagem, das soldas e das fixações.

Também foi dedicado muito tempo de supervisão à fabricação das peças, uma vez que o trabalho foi manual e utilizou técnicas simples para medição de ângulos (transferidor), cortes e identificação das peças.

A partir dos recursos computacionais utilizados na concepção e desenvolvimento do projeto, foi possível viabilizar um trançado complexo a partir da extração e organização dos dados (Figura 5). A lógica de posicionamento do encordoamento projetado está intrinsecamente ligada aos fatores estruturais, ao posicionamento geral da estrutura, aos fatores de incidência solar e à especificação técnica do material das cordas. Ou seja, todo o projeto mantém relação entre suas variáveis, não sendo possível desassociar a geração da forma de seus parâmetros.

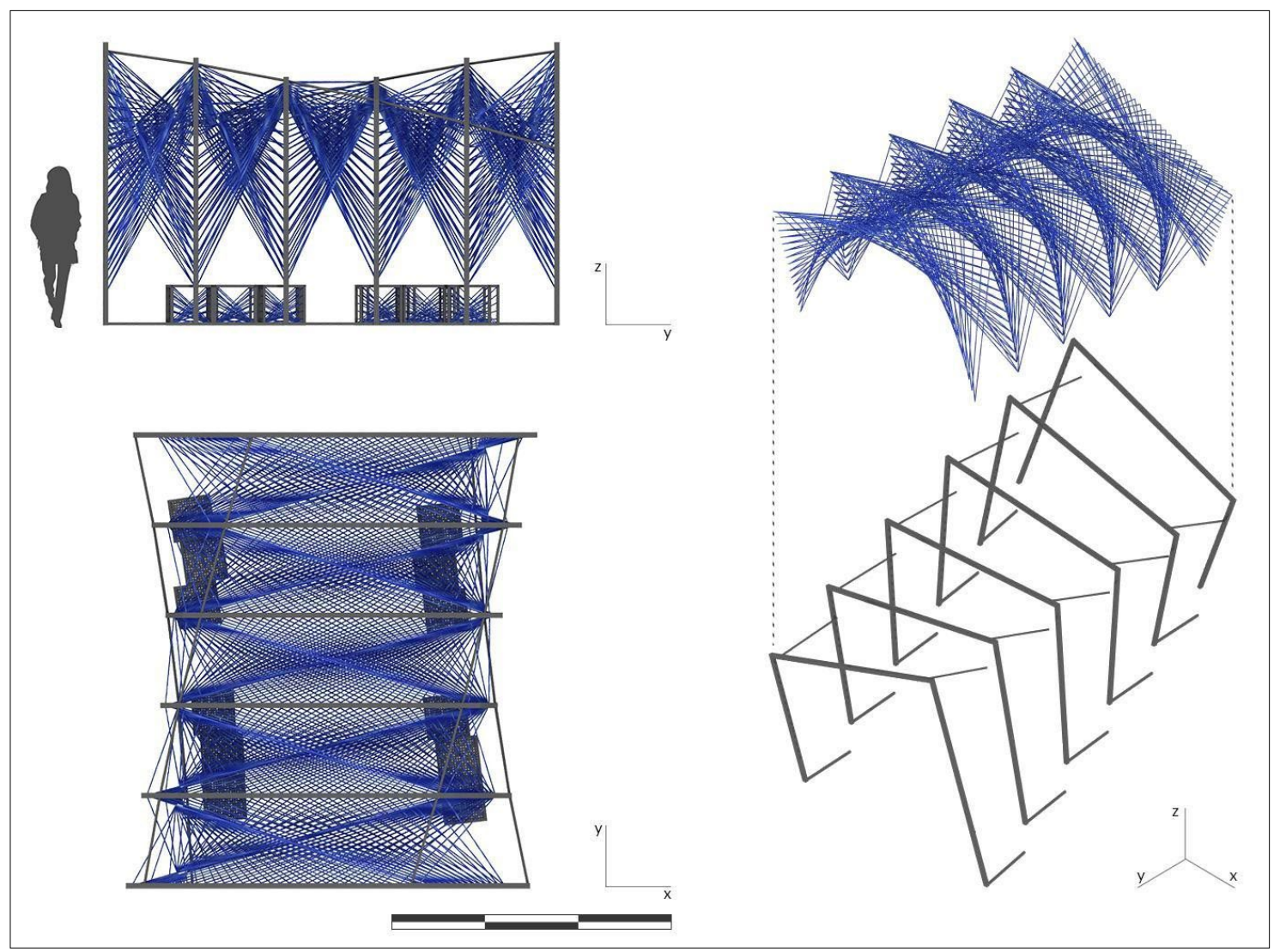

Figura 5: Vista lateral, vista superior e isométrica do projeto

Fonte: Elaborada pelos autores do projeto
A extração dos dados para a execução do encordoamento foi prevista no algoritmo e realizada a partir das observações obtidas na construção do modelo em escala (Figura 6). Foram estabelecidas quatro camadas de trançado que se sobrepõem. O documento gerado para esta ordem foi uma planilha que identificou passo a passo a ordem do trançado e pontos de fixação.

Além disso, os dados de quantificação dos materiais foram extraídos e sistematizados através do algoritmo, priorizando o consumo consciente e a economia de materiais. 
Ao todo, foi necessário um dia para a instalação e montagem da estrutura (Figura 7), que contou com equipe técnica especializada, e três dias para a execução do trançado, que contou com o trabalho voluntário de autores, pesquisadores e sociedade civil.
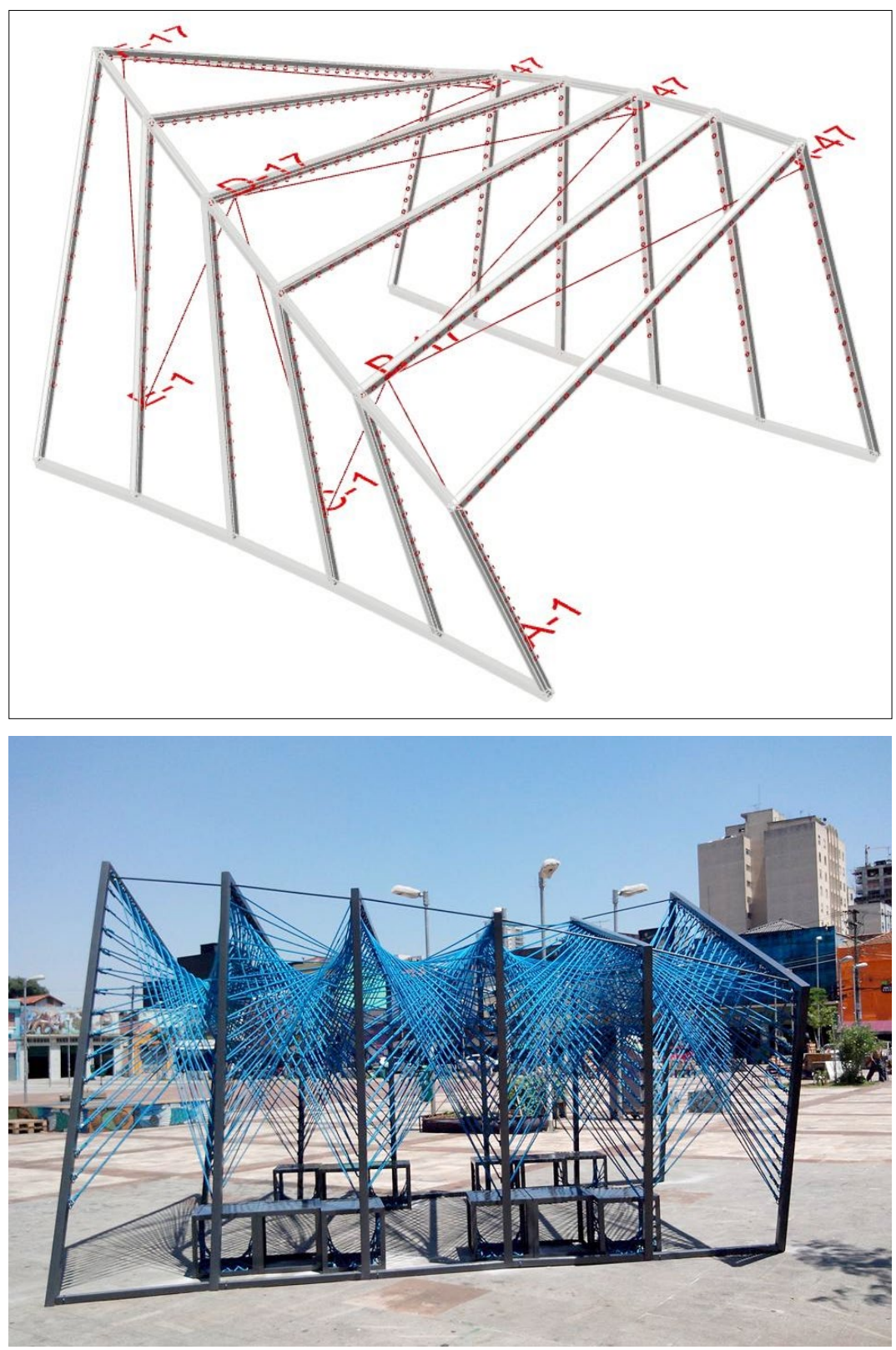

\section{DISCUSSÃO}

A produção e instalação do mobiliário Trançado contribui para, de um lado, a aplicação, reflexão e validação real do projeto feito a partir de recursos computacionais, modelagem paramétrica e fabricação digital e, de outro, contribui para o caráter de laboratório proposto pelos coletivos e sociedade civil organizada atuantes no Largo da Batata, gerando dados de utilização do espaço e insumos de pesquisa para a discussão sobre o uso e a apropriação do espaço público.
Figura 6: Modelo digital com dados de posicionamento e ordem de trançado das cordas

Fonte: Elaborada pelos autores do projeto

Figura 7: Foto do mobiliário Trançado

Fonte: Nayara Benatti 
Figura 8: Foto do mobiliário Trançado ocupado

Fonte: Thiago Miagy
O projeto ainda fomenta e incentiva a discussão sobre a aplicação e manutenção de materiais que não são comumente usados em mobiliários urbanos e a importância da variabilidade de propostas de design na exploração de aspectos funcionais e estéticos dos mobiliários atualmente implantados na cidade (Figura 8). Também foi identificado o uso inesperado do mobiliário por crianças e jovens, que se penduram nas cordas - um uso não previsto inicialmente e que demanda manutenção constante para que o mobiliário permaneça em bom estado.

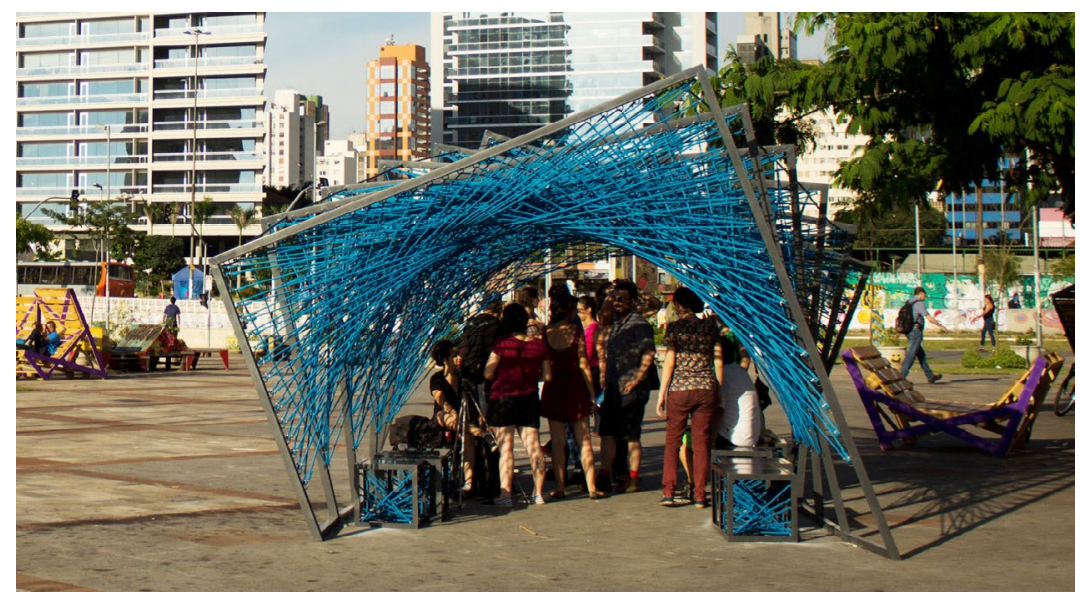

Foi realizada uma pesquisa de pós-ocupação pelos institutos organizadores do concurso, A Cidade Precisa de Você e Ipiu, entre abril e maio de 2016, quatro meses após a instalação do mobiliário. A pesquisa contou com 400 entrevistas com frequentadores do Largo da Batata.

Entre os dados mais relevantes publicados pela pesquisa, foi constatado que $80,8 \%$ dos entrevistados costumam frequentar o Largo da Batata, sendo que $34,3 \%$ deles frequentam diariamente o local. Também foi identificado que $81,8 \%$ dos entrevistados acreditam que o local tem sido mais frequentado após a instalação dos mobiliários, e sua implantação melhorou a interação entre as pessoas. Ao serem questionados sobre a aprovação de cada mobiliário separadamente, 83,3\% dos entrevistados relataram aprovar o mobiliário Trançado (a pesquisa possui margem de erro de 5\% para mais ou para menos) (ANTUNES; SOBRAL; KARPISCHEK, 2016).

Ainda segundo a pesquisa de pós-ocupação, os mobiliários vêm sendo fator de mudança no local.

Em uma cidade onde há pouco mobiliário urbano (e quase sem inovação no seu desenho), propor equipamentos que sejam o resultado de testes com mobiliário temporário, de análises de uso, mapeamento de dinâmicas sociais e envolvendo vários setores da sociedade (sociedade civil, terceiro setor, poder público e organizações privadas) é um importante avanço na qualidade dos espaços públicos. (ANTUNES; SOBRAL; KARPISCHEK, 2016, p. 8)

Muitos eventos, como festas e rodas de música e dança, passaram a acontecer por causa da implantação, e foi identificado o aumento da interação entre as pessoas e frequentadores do largo - jovens, adultos, moradores de rua, skatistas etc. (ANTUNES; SOBRAL; KARPISCHEK, 2016).

\section{CONSIDERAÇÕES FINAIS}

Alguns aspectos da relevância dos recursos computacionais para o processo de projeto ficam evidentes: o potencial da parametrização na 
concepção facilitou revisões e evoluções do processo, demonstrando aspectos positivos em abranger a pesquisa coletiva e a inserção de dados que estimulam a integração do contexto físico e cultural do local.

Quanto à fase de concepção e desenvolvimento, a prototipagem rápida mostrou-se facilitadora da materialização de modelos, o que possibilita o teste do projeto e torna seus problemas mais visíveis. Deste modo, a equipe teve amparo em visualizar problemas que dificilmente poderiam ser identificados sem o uso dessas tecnologias, o que levou a um refinamento e qualificação do processo de projeto. Além disso, a construção do modelo com fabricação digital possibilitou a produção protótipos em duas cidades, com a rapidez necessária para que a produção fosse viabilizada dentro dos prazos.

Uma das vantagens de desenvolver o projeto através de algoritmo é ter o modelo inteiramente disponível em dados, viabilizando assim o sistema file-to-factory (do arquivo para a fábrica), caracterizado pela comunicação direta entre o arquivo digital e o equipamento de produção controlado numericamente, utilizado para a fabricação do projeto (PUPO, 2009, p. 103). Esse processo interfere na maneira como o arquiteto documenta o projeto, eliminando a necessidade de documentação padrão encontrada na indústria da construção civil (plantas, cortes, elevações).

Embora em ascensão e conhecidas pela facilidade de customização da produção, as práticas de fabricação digital aplicada à arquitetura ainda são restritas em São Paulo. Não foi possível encaixar no orçamento disponível os valores estimados da fabricação usando estas técnicas.

Outro fator crucial para a mudança de estratégia de fabricação foi a inviabilidade do tempo de resposta do orçamento, dificultado pela exigência da indústria em realizá-lo apenas com a documentação tradicional das peças, além da pouca receptividade em colocar na linha de produção a fabricação de uma única unidade de um projeto, o que demonstra pouco alinhamento da indústria com preceitos de fabricação digital.

Contudo, a concepção, fabricação e instalação do mobiliário demonstrou receptividade por parte dos organizadores do concurso, subprefeitura e usuários, ascendendo a discussão sobre a relevância do design também enquanto experiência a partir da estética que pode ser explorada com o uso de recursos computacionais, sem desconsiderar fatores funcionais.

Assim, foi possível observar, no decorrer das etapas, como o uso da parametrização foi fundamental para o desenvolvimento do projeto em diversos aspectos: facilidade em articular parâmetros; possibilidade de simulações; facilidade de revisão; prototipagem rápida para testes; viabilidade de trançado complexo.

\section{REFERÊNCIAS}

ANTUNES, B.; SOBRAL, L.; KARPISCHEK, T. (Orgs.). Batatalab, a publicação: concurso de mobiliário urbano realizado por Instituto A Cidade Precisa de Você + Ipiu. São Paulo: Instituto A Cidade Precisa de Você, 2016. Disponível em: <https://goo.gl/yVFjHk>. Acesso em: 31 out. 2017.

$\begin{array}{llr}\text { CASTELLANO, } & \text { D. } & \text { Humanizing } \\ \text { parametricism. In: } & \text { ACADIA } 2011\end{array}$ REGIONAL CONFERENCE, 1., 2011, Lincoln. Proceedings... Lincoln: University of Nebraska Press, 2011. p. 275-279.

DAVIS, D.; BURRY, J.; BURRY, M. Untangling parametric schemata: enhancing collaboration through modular programming.
In: COMPUTER-AIDED ARCHITECTURAL DESIGN FUTURES 2011, 14., 2011, Liège. Proceedings... Liège: Les Éditions de l'Université de Liège, 2011. p. 55-68.

INSTITUTO A CIDADE PRECISA DE VOCÊ. Batatalab: concurso de mobiliário urbano no Largo da Batata. 2015.

INSTITUTO A CIDADE PRECISA DE VOCÉ; INSTITUTO DE PESQUISA E INOVAÇÃO EM URBANISMO. Edital: chamada pública de projetos para o concurso Batatalab. São Paulo: Instituto A Cidade Precisa de Você; Ipiu, 2015.

KRIPPENDORFF, K. Intrinsic motivation and human-centered design. Theoretical Issues in Ergonomic Science, Abingdon, v. 5, n. 1, 
p. 43-72, 2004. Disponível em: <https://goo. gl/XVW49i>. Acesso em: 31 out. 2017.

LAWSON, B. How designers think: the design process demystified. 4. ed. Amsterdam: Elsevier, 2005.

OXMAN, R. Theory and design in the first digital age. Design Studies, Amsterdam, v. 27, n. 3, p. 229-265, 2006.

OXMAN, R.; GU, N. Theories and models of parametric design thinking. In: EDUCATION AND RESEARCH IN COMPUTER AIDED ARCHITECTURAL DESIGN IN EUROPE, 33.,
2015, Vienna. Proceedings... Vienna: Vienna University of Technology, 2015. v. 2, p. 477-482.

PUPO, R. T. Inserção da prototipagem e fabricação digitais no processo de projeto: um novo desafio para o ensino de arquitetura. 2009. 240 f. Tese (Doutorado em Engenharia Civil) - Faculdade de Engenharia Civil, Arquitetura e Urbanismo, Universidade de Campinas, Campinas, 2009.

WOODBURY, R. F. Elements of parametric design. London: Routledge, 2010.

\section{Dyego Digiandomenico \\ dyego.sd@gmail.com}

\section{Gabriele Landim}

gabriele.landim@gmail.com

\section{Henrique Fischer}

arq.fischer@gmail.com 